bowel after resection of the whole or part of the sigmoid flexure and when no adequate lower stump of bowel is obtainable should prove useful, as it is a great improvement upon the more usual method of establishing a permanent colotomy. And it should be quite as safe, as the condition is for all practical purposes a colotomy during the first week after the operation.

One of the chief advantages of this operation is that it enables the continuity of the bowel to be restored satisfactorily in a situation where stitching is out of the question. Another great advantage is that the bowels can be freely opened on the day after the operation if necessary, without any fear of rupture or leakage or any danger of soiling the peritoneum, as the sigmoid flexure and tube are continuous and gas-tight. The fact that apposition between the two ends of the bowel is not very accurate does not matter, in view of the fact that no strain at all is thrown upon the line of union for nearly a week after the operation owing to the presence of the glass tnbe. I was doubtful at first if the presence of a long glass tube in the rectum would cause severe pain or other trouble, but beyond some swelling of the anus there was no pain or other inconvenience from the presence of the tube. In the future, however, I shall use a specially made rubber tube in place of the glass one. These special tubes have a hardened grooved end and have been made for me by Messrs. Allen and Hanburys.

The formation of a fæcal fistula in this case $I$ attribute to th fact that the nurse had not got the rectum empty and in consequence, the patient being in the Trendelenburg position, the peritonenm became soiled directly the bowel was divided.

Cavendish-place, W.

\section{THE DIAGNOSIS OF PERFORATING AND OF CHRONIC DUODENAL ULCER.}

\section{By Sir JOHN F. H. BROADBENT, BART., M.D. OXoN., F.R.C.P. LOND., \\ PHYSICIAN TO OUT-PATIENTS, ST. MARY'S HOSPITAL; AND ASSISTANI} PHYSICIAN TO THE LONDON FEVER HOSPITAL.

OF recent years attention has been directed to the subject of dnodenal ulcer, more especially in reference to sudden perforation of the ulcer. A correct diagnosis of this condition is more commonly arrived at now than was the case some eight years ago, when in a paper by Dr. Weir ${ }^{2}$ of New York out of 51 cases collected by him a correct diagnosis was arrived at in only 13 instances, the condition being mistaken most commonly for appendicitis or perforated gastric ulcer, and in some instances for intestinal obstruction. Since that date numerous papers have been published on this subject by various authors.

In this communication, while referring to the question of perforation, I purpose more particularly to deal with the symptoms of non-perforating ulcer and its sequelæ, the diagnosis of which is often a matter of considerable difficulty.

\section{Etiology of Duodenal Ulcer.}

Burns are mentioned in surgical text-books as a canse of duodenal ulcer. Holmes ${ }^{3}$ records the occurrence of duodenal ulcer in 16 out of 165 cases of burns. Collin found it present in 38 out of 297 cases collected. Perry and Shaw met with it in five cases out of 149 collected from the Gay's Hospital post-mortem records. Various explanations have been suggested for this association of duodenal ulcer with burns. The most plausible would seem to be that the congested condition of the intestines is the predisposing, and septic embolism or thrombosis of a small vessel followed by digestion of the necrotic area the determining, cause. Burns are, however, present in only a very small proportion of cases and cannot be regarded as important etiological factors.

It is noteworthy that while gastric ulcer is most fraquently met with in young anæmic women, by far the greater proportion of duodenal ulcers, 79 per cent. according to Collin's statistics, occur in strong middle-aged men and are not associated with anæmia. Tobacco and alcohol, to which men are more addicted than women and which are supposed to

A paper read before the New Cross Medical Society in January

2 New York Medical Record, May, 1900, p. 749

System of Surgery, vol i., p. 733 .

4 Thise de Paris, 1896 .

intensify the acidity of the gastric juice, have therefore been thought to predispose to duodenal nlcer. There is certainly a history of alcoholism in a large number of cases, but so few comparatively out of the vast number of alcoholics and heavy smokers suffer from duodenal ulcer that this is scarcely an adequate explanation for its preponderance in men Possibly the constant stooping and lifting associated with laborious occupations combined with irregular meals and coarse food may play some part in its production, for it is more frequently met with in the working classes.

Ulceration occurs most frequently in the first part of the duodenum which is exposed to the action of the acid gastric contents before they are nentrailsed by the alkaline flow of pancreatic juice and bile. It would seem most rational therefore to attribate duodenal ulcer to the same causes as gastric ulcer-namely, the solvent action of the hydrochloric acid secreted by the stomach on a portion of tissue the vitality of which has been lowered by traumatism or by the cutting off of its blood-supply by embolism or thrombosis. Anatomically it resembles a gastric ulcer. It may be pnnched out with sharp clean-cut edges, and perforate suddenly without previous warning, or the edges may be thickened and heaped up so that the ulcer presents a funnelshaped appearance. Adhesions may form between the inflamed peritoneum at the base of the ulcer and adjoining stiructures, or cicatricial contraction occur with resulting narrowing of the lumen of the duodenum. Not infrequently more than one ulcer is present.

\section{Perforation of Uleer.}

The duodenum is so situated anatomically, being deeply placed behind the right lobe of the liver and the gall-bladder that when perforation of an ulcer takes place the contents of the gut do not as a rule escape directly into the general peritoneal cavity, as is the case in perforation of a gastric ulcer. More commonly the escaped fluid tends to travel along the posterior aspect of the hepatic flexure of the colon, thence gravitate downwards to the front of the right kidney and eventually along the outer side of the ascending colon to the right iliac fossa, setting up peritoneal inflammation in its track, which may simulate renal trouble or appendicitis. Frequently the peritonitis is localised in the first instance to the right flank, so that the symptoms of collapse are not so marked as in gastric ulcer. Moreover, the duodenum is not like the stomach, a large sac full of fluid, but is only filled as the gastric contents flow into it during digestion, and it may be practically empty at the time of perforation, so that the extravasation is limited in amount.

Symptoms of Perforation.

Turning now to the symptoms of perforation, the common story is that a strong healthy-looking man while at work, lifting a heavy weight, or perhaps shortly after a meal, is suddenly seized with violent pain in the abdomen in the right epigastric or hypochondriac region, followed immediately or after a short interval by vomiting. Symptoms of collapse may set in almost immediately if general peritonitis results, but they are less severe as a rule than in perforation of a gastric ulcer and may be ill marked or deferred for some hours or even be absent altogether. For, as has already been said, the resulting peritonitis is frequently limited to the right side of the abdomen. There will then be pain tenderness, and rigidity in the right flank, and the tenderness may be marked not only in front but in the loin behind the right kidney. The movement of the abdomen in respira. tion will be restricted, more especially on the right side. The temperature will be raised to perhaps $101^{\circ}$ or $102^{\circ} \mathrm{F}$. the pulse-rate increased to 100 or 112 , and the aspect of the patient will be characteristic of abdominal trouble. The prognosis for operation at this stage will be good, but if deferred too long the peritonitis may become general by the oreaking down of adhesions, or failing this a subphrenic abscess may result from extravasation upwards between the right lobe of the liver and the diaphragm.

The following three cases illustrate (1) localisation of the peritonitis to the right flank; (2) general peritonitis ; and (3) formation of subphrenic abscess.

CASE 1.-A man, aged 31 years, was admitted under my care while in charge of the wards to St. Mary's Hospital on August 21st, 1906, complaining of severe pain in the right hypochondriac region. He said that he had been quite well till two days before admission when he was seized while at work with severe pain in the right hypochondriac region and vomiting about one hour after his dinner. The pain became more severe next day, and the 
vomiting persisted. Previously to this attack there was no history of pain or indigestion in any form. He had been a fairly heary drinker. On admission the face was flushed and anxions, the pulse was 100 , and the temperature was $101^{\circ} \mathrm{F}$. There were tenderness and rigidity in the right flank, most marked behind in the lumbar region. There was immobility of the right upper segment of the abdomen in respiration, but elsewhere the abdomen moved fairly well and there was no general tenderness or rigidity. From the sudden onset of the pain and vomiting and the evidence of some inflammatory trouble in the right upper quadrant of the abdomen I diagnosed perforation of a duodenal ulcer. From the localisation of the tenderness and rigidity to the right lumbar region I thought it was probable that the contents of the duodenum had gravitated downwards along the colon to the front of the right kidney. I therefore asked Mr. W. H. Clayton-Greene to operate and suggested that he should explore the right flank and cut down on the right kidney. Nothing was found extra-peritoneally, but on incising the peritoneum an abscess was found immediately in front of the kidney from which about two ounces of pus were evacuated. The abscess was localised and shut in by adhesions, so no attempt was made to suture the ulcer in case the breaking down of adhesions might lead to infection of the general peritoneum. A drainage-tube was inserted and the patient made a rapid and excellent recovery.

CASE 2.-A man, aged 26 years, was admitted to St. Mary's Hospital on August 24th, 1900, being sent as a case of appendicitis. He stated that he was quite well till the day before. He was then lifting a heavy weight when he was suddenly seized with severe pain in the abdomen, followed by vomiting. He was brought to the hospital on the next day. On admission he was collapsed, the face was pinched, pale, and anxious, the temperature was $99^{\circ} \mathrm{F}$., the pulse was 124, and the respirations were 36 . The abdomen was distended and scarcely moved in respiration, there were tenderness and some rigidity in the right epigastric region, and the legs were drawn up. The liver dulness was absent and on tapping two coins together and auscultating over the liver area there was a well-marked bell note. There was occasional hiccough but no vomiting. Mr. H. S. Collier operated at once. On opening the abdomen free gas escaped and there was recent general peritonitis. A perforated ulcer was found in the first part of the duodenum, and was sutured. The patient was, however, in an almost desperate state and he died the same evening. At the necropsy there were recent general peritonitis and a small collection of pus between the liver and the diaphragm. In the duodenum about one inch from the pylorus were three ulcers, one of which had perforated and had been sutured.

These two cases were fairly straightforward and the diagnosis did not present any great difficulty. When, however, a subphrenic abscess results from formation of adhesions and the case is not seen till some days or weeks after the perforation has taken place the diagnosis may present considerable difficulty as the following case will illustrate.

CASE 3.-A man, aged 60 years, was admitted to hospital under the care of Dr. W. B. Cheadle on March 16th, 1900. He said that he was taken ill suddenly five weeks previously with severe pain in the right side of the abdomen, followed by vomiting. He went to bed and stayed there a week, when he got up again, but a few days later was seized with severe pain in the left side of the abdomen, vomited, and had several rigors. He remained in bed and had only had liquid food for the last week, but cough and increasing dyspncea compelled him to go to the hospital. On admission he was pale and emaciated, with an anxious expression and very short of breath. The pulse was 140 , the temperature was $101 \cdot 8^{\circ} \mathrm{F}$., and the respirations were 34 . The abdomen was distended and tympanitic and did not move freely in respiration. There were signs of effasion in the left pleural cavity. The heart was somewhat displaced ; otherwise it was normal. An exploring needle was inserted below the angle of the left scapula and offensive pus was withdrawn. A diagnosis of empyema was made and he was taken to the theatre. A portion of rib was resected just below the puncture of the exploring needle, and a quantity of clear serous fluid escaped from the left pleural cavity. The patient was too ill for further exploration and was put back to bed. He died at 3 P.M. on the next day. At the necropsy a large subphreaic abscess was found bounded above by the diaphragm, below by the upper surface of the liver and stomach, and to the left by the spleen, which was riddled with small abscesses. It was shut off from the general peritoneal cavity by adhesions, but the pancreas was gangrenous and almost entirely destroyed. There were two ulcers in the duodenum, one of which had perforated and given rise to the subphrenic abscess.

In this case the perforation had apparently taken place five weeks before admission, when the patient was attacked with sudden pain in the right side, followed by vomiting. This was thought by his medical man to be an attack of biliary colic. The leakage had been apparently small and was circumscribed by adhesions which were broken down when the patient got about again and led to extensive suppuration and a subphrenic abscess. The most prominent symptom on admission was extreme dyspnoea, which seemed to be accounted for by extensive plearal effusion. The exploring needle when inserted must have gone through the pleura into the subphrenic abscess which pushed up the diaphragm, since offensive pus was withdrawn, and the subsequent discovery of clear fluid when operating for empyema came as a surprise. It is, however, by no means uncommon to find clear fluid in the pleural cavity in association with suppura. tion beneath the diaphragm and I have seen it in two other instarces with subphrenic abscess and in one case with a liver abscess. I am indebted to Dr. Cheadle for permission to publish these two cases, which I had the opportunity of seeing when medical registrar.

\section{Chronic Ulcer of the Duodenum.}

The symptoms and physical signs that may be present in this affection are :-

Pain, usually felt in the right epigastric or right hypochondriac region but sometimes not localised to any particular spot, is one of the most constant symptoms and may persist on and off for some years. It may be slight and be ascribed to "indigestion," or it may be severe and described as gnawing, sharp, or griping in character. Sometimes it is paroxysmal and may be attributed to biliary colic, as in one case I saw in which attacks had persisted on and off for five years. It is not, as a rule, immediately induced or aggravated by ingestion of food, as in gastric ulcer, but may be relieved thereby, as the closure of the pylorus which ensues will temporarily arrest the flow of gastric contents into the dnodenum. It may set in an hour or two after meals but frequently the patient does not notice any definite interval or even any causal relation between the taking of food and the onset of the pain. Sometimes it may be almost constant day and night as a dull aching pain with exacerbations at irregular intervals.

Vomiting, which is a comparatively rare antecedent of perforation (it was present in only 17 per cent. of the cases of acute perforation collected by Weir), is, I think, a fairly constant feature in cases of chronic duodenal ulcer. It was present at one time or other in all the cases which I hare seen. It is not always persistent or frequent but may occur at irregular intervals without any special relation to meals. Sometimes it appears to afford relief to the pain by emptying the stomach, so that the flow into the duodenum ceases, so much so that a patient may put his finger down his throat to make himself sick. Large quantities may be vomited up at the end of the day when there is dilatation of the stomach induced by cicatrisation of the ulcer and narrowing of the duodenum.

Hamorrhage is stated by Krauss to occur in about 33 per cent. of cases, but in 151 cases collected by Perry and Shaw it was noted in 23 only, or about 13 per cent. Both bæmatemesis and melæna may occur, but melæna is more significant when present alone, as when boti are present it will be difficult to exclude gastric ulcer. My experience is that neither is very common. Hæmatemesis and melæna occurred in two and melæna alone in two out of the 12 cases on which this paper is based. In one of these the hæmorrhage recurred a year after the successful relief of all symptoms by gastro-enterostomy, so it is probable that the nlcer was really not in the duodenum itself but near the pyloric orifice of the stomach. It is possible that melæna may escape the notice of the patient, as he may not realise that the black, tarry motions which he passes contain blood.

The following case can be quoted as an instance of hæmorrhage. A man, aged 49 years, was brought to St. Mary's Hospital in Jaly, 1905, with a history that he had fallen down in the street vomiting blood. On admission he was profoundly anæmic; the pulse was small and rapid, and after admission there was profuse melæna. He said that he had never vomited or passed blood before this attack, but for the last six years had suffered from indigestion and for the last two 
years had pain in the epigastrium almost constantly about an hour after meals. Nutrient enemate were administered and no food was given by the mouth for three days. A little peptonised milk was then given by the mouth but the hæmorrhage recurred, so recourse was again had to nutrients. As he was losing ground and getting weaker and thinner it was decided to perform the operation of gastroenterostomy and on July 21st, a week after admission, this was done by Mr. Olayton-Greene. There was no thickening of the duodenum and no adhesions or any external evidence of an ulcer were to be seen at the operation, but the interior of the duodenum was not examined. He made a rapid and satisfactory recovery; there was no return of hæmorrhage and he was soon able to eat any kind of solid food without discomfort.

Dilatation of the stomach.-This I consider a symptom of considerable diagnostic importance. It may result from stenosis of the duodenum or pylorus by cicatrisation of an ulcer and there may be considerable thickening of the wall of the duodenum or scarring and puckering of its peritoneal surface, and in two cases of this nature I have observed well-marked peristalsis of the stomach wall. In some cases there are adhesions between the duodenum and adjacent structures or cicatricial bands which may give rise to obstruction, but in others in which dilatation of the stomach is present no obvious cause can be made out at the operation for gastro-enterostomy when this is performed. Of course the interior of the duodenum is not investigated in those cases, and it is possible that some narrowing of the lumen is present. In two fatal cases, however, I have found marked dilatation of the stomach in which at the necropsy no stenosis of the duodenum could be made out. In one of these three ulcers were present. It seems possible, therefore, that the dilatation of the stomach may be gradually brought about by reflex spasm of the pylorus, due to a reflex inhibition of its dilating mechanism, when the gastric contents begin to flow over the ulcerated surface. If so, this would explain the presence of dilatation of the stomach in those cases in which at the operation no thickening of the duodenum or definite evidence of obstruction can be made out. Peristalsis of the stomach wall would only be expected to occur when definite obstruction had been produced by cicatricial contraction of an ulcer or adhesions. In the two cases in which I have observed it well-marked thickening and scarring of the duodenum were present.

The following cases illustrate dilatation of the stomach in association with chronic duodensl ulcer.

CASE 1.-A man, aged 48 years, went to my outpatient department at St. Mary's Hospital in August, 1907, complaining of vomiting large quantities of food, chiefly at night. There had been no pain after meals recently, but some time before he said he had attacks of "indigestion" There was no history of melæna or hæmatemesis. He had not been a heavy drinker but had taken his two or three pints of beer daily. There was great dilatation of the stomach, which extended well below the umbilicus, as ascertained by the combined succassion and auscultation method. He was admitted to the hospital on Sept. 7th and when in bed well-marked peristalsis of the stomach from 'eft to right was observed on several occasions. This was well brought out by the administration of bicarbonate of sodium and tartaric acid. On washing out the stomach and testing its capacity it sas found to hold 102 ounces. No tumour conld be felt in the region of the pylorus and there was no tenderness in that region. The symptoms and physical signs clearly pointed to dilatation of the stomach from obstruction at or just beyond the pylorus, so I decided on the operation of gastroenterostomy for its relief. Mr. Olayton-Greene performed the operation on Sept. 19th. At the operation the stomach was seen to be enormously dilated and its walls were hypertrophied. There was no thickening of the pylorus but there were numerous adhesions in the neighbourbood of the dnodenum and scarring of its peritoneal wall. The patient subsequently made an uninterrupted recovery. There was no more vomiting and he rapidly gained weight and went out feeling quite well.

In this case there was no evidence of definite symptoms pointing to duodenal ulcer except that of some "indigestion" a long time before, but from what was seen at the operation it was clear that cicatrisation of a duodenal ulcer and inflammation of its peritoneal surface were the cause of the dilatation of the stomach to which the symptoms pointed when he came for treatment.
The next three cases are very similar to the above.

CASE 2-A man, aged 33 years, was admitted to St. Mary's Hospital in September, 1907, while I had charge of the wards. He said that he had had attacks of pain in the right epigastric region and vomiting on and off at intervals for the last five years, sometimes being free from them over a month at a time. Vomiting relieved the pain but neither the onset of vomiting nor the pain bore any direct relation to ingestion of food. There was no history of melæna or hæmatemesis. He was not addicted to alcohol. The stomach was very dilated, a succussion splash being audible below the umbilicus. There was no tumour to be felt at the pylorus and peristalsis was never observed. No tender area could he detected on palpation. A test-meal showed the presence of free $\mathrm{BCl}$, the acidity boing estimated at 0.024 per cent. of free $\mathrm{HOl}$ by Dr. W. H. Willcox. On Nov. 8th Mr. V. W. Low performed the operation of gastro. enterostomy. There were no thickening of the pylorus or duodenum and no scarring or puckering and only a few adhesions were found in the neighbourhood of the latter. The patient had no return of the pain or vomiting and made a rapid recovery.

In this case no obvious obstruction could be made out in the duodenum at the operation and little evidence of nlcer from the exterior but there could be no donbt that a duodenal ulcer was the cause of the symptoms and of the gastric dilatation.

CASE 3.-Three years ago I was asked to see in consulta tion a man, aged 40 years, who for six years had suffered from "dyspepsia" and who during the last six months had had severe pain in the right epigastric and hypochondriac region usually about half an hour after meals. During the last three months he had vomited enormous quantities at intervala, chiefly at night. 'He was very emaciated and had rapidly lost flesh of late. There was no history of melæna or hæmatemesis. On examination I found enormous dilatation of the stomach. There was no tumour in the pylorie region but an area of tenderness on palpation under the right costal margin. I advised the operation of gastro-enterostomy which was successfully performed. There were adhesions and considerable thickening of the duodenum. He made an excellent recovery and in two months gained a stone in weight and is now in excellent health and has had no return of symptoms.

CASE 4.--In October, 1906, I was asked to see a lady, aged about 35 years, who for three months had had pain in the left epigastrium and irregular attacks: of vomiting of large quantities of food. Four years previonsly she had had hiematemesis and melæna and since then she had had at intervals attacks of pain and vomiting. On examination the stomach was found to be enormously dilated and on several oceasions well-marked peristalsis of the stomach wall was observed. I concluded that the dilatation was due to obstruction in the duodenum from a cicatrised ulcer and advised the operation of gastroenterostomy, which was successfally performed. This I did not see, but I was informed after that there were a mass of adhesions in the neighbourhood of, and considerable thickening of, the dnodenum, giving rise to considerable obstruction. She made a good recovery.

The following case illustrates the chronicity of the affection and the tendency to recurrence even when the symptoms have been in abeyance for some considerable period of time.

CASE 5-A man, aged 52 years, went to my out-patient department at St. Mary's Hospital on Jan. 3rd, 1908, complaining of pain in the right epigastric region and attacks of romiting. His history was as follows. Ten years ago he was first troubled with " indigestion" pain in the epigastric region some two or three hours after meals, with occasional attacks of vomiting. This persisted on and off for six years when he had a severe attack of melæna. As a result of careful dieting, complete rest, and change of air his symptoms completely disappeared and he enjoyed good health for about six montbs. The pain and vomiting then recurred and had persisted on and off for the last four years. Latterly the pain had become more or less conetant and the vomiting, instead of setting in a few hours after meals, had occurred chiefly at night and was more profuse. $\mathrm{He}$ had been losing flesh rapidly of late and dieting failed to relieve the symptoms. He was a strong, well-made man but very poorly nourished and was strictly temperate. On examination the stomach was found to be greatly dilated and there was some tenderness on deep pressure just below the seventh right costal cartilage. No 
tumour could be felt. From the history of the case, attacks of pain and vomiting extending over nearly ten years, melæna, and symptoms which now pointed to some obstruction at or beyond the pyloras, with pain in the right hypochondriac region, I diagnosed chronic duodenal ulcer, partial cicatrisation of which was giving rise to stenosis of the duodenum and consequent dilatation of the stomach. I therefore advised the operation of gastro-jejunostomy which Mr. Low successfully performed on Jan. 10th. At the operation a few adhesions were found in the neighbourhood of the duodenum and a small hard cicatrix was felt on the anterior aspect of the first part of the duodenum. There was no recurrence of vomiting after the operation and he is now free from pain and able to take food without any pain or discomfort.

Diagnosis.-An accurate diagnosis can usually be made by careful consideration of the history of the case and the chronic character of the symptoms rather than by physical signs, which are often very indefinite. In a typical case the patient will be a middle-aged man with a history that he has suffered on and off for some years with pain and vomiting. He may tell you that at first the pain usually set in from two to three hours after meals and was sometimes temporarily relieved by taking food or by vomiting. Vomiting sometimes accompanied the pain but was not so constant or persistent a symptom. These symptoms were not so severe as to compel him to leave off work and as a result of careful dieting they may have been in abeyance for weeks at a time, but they tended to recur on resuming ordinary diet. He may bave sought advice because they have been increasing in severity and the pain has become more or less constant and is not relieved by dieting. Possibly neither the pain nor romiting now has any direct relation to ingestion of food, and there may be no definite area of tenderness on palpation of the abdomen. Here the diagnosis must be based mainly on careful consideration of the history and chronicity of the symptoms.

A severe attack of melæna or of melæna and hæmatemesis may have brought matters to a crisis. In this event there can be little difficulty in arriving at a correct diagnosis. Again, the patient may say that recently the symptoms have altered in character, that the pain is less or is now griping in character instead of sharp and gnawing or has disappeared, and that the vomiting now comes on at night or every two or three days and a very large quantity is brought up each time. Examination will reveal considerable dilatation of the stomach and it may be that on careful inspection peristalsis of the stomach wall is observed. The presence of these physical signs with a history such as that given above will leave no doubt as to the correct diagnosis. If the ulcer be cicatrised completely there will be no pain and the previous symptoms may have been almost forgotten, but if there be only partial cicatrisation or fresh ulcers have succeeded one already cicatrised, pain will be present and perhaps deep-seated tenderness on palpation below the seventh costal cartilage.

Differential diagnosis. - The seat and character of the pain, the indefinite relation of both pain and romiting when this occurs to ingestion of food, and the absence of hæmatemesis will, as a rule, serve to distinguish duodenal from gastric vloer. Hæmatemesis and melæna may occur but the former is comparatively rare. Melæna in association with attacks of pain in the right hypochondriac region will be very signifi. cant. A history of chronic indigestion occurring after middle life may suggest malignant disease of the stomach, but the chronicity and intermittent character of the symptoms which may have lasted some years, and absence of severe emaciation and cachexia, will usually enable an accurate diagnosis to be made. In doubtful cases the evidence afforded by a test meal will be of great value, as in duodenal alcer there is often excess and seldom absence of free hydrochloric acid. When gastric dilatation is present and peristalsis shows evidence of obstruction at or beyond the pylorus, the question of new growth of the pylorus must be considered. The absence of any tumour in the pyloric region, and the history of attacks of vomiting and pain on and off for some months or years in the right epigastric or hypochondriac region will usually enable a diagnosis to be made between these two affections. It will be advisable in all cases before considering operation to remember to exclude the possibility of gastric crises from tabes dorsalis.

Treatment.-There can be no question that the only satisfactory method of treatment as soon as a diagnosis is arrived at is by the operation of gastro-jejunostomy. This, of course, short-circuits the duodenum and usually all symptoms subside rapidly after the operation; the result is, as a rule, most satisfactory. Rectal feeding for some days and subsequent careful dieting may give relief and apparently are successful in some cases, but it must be remembered that there is a tendency for the ulcer to recur and that even when the ulcer does heal satisfactorily cicatricial contraction may give rise to obstruction and lead to gastric dilatation for which the same operation will eventually be required.

Seymour-street, $\mathrm{w}$.

\section{A METHOD OF ADMINISTERING SOLIDS IN CASES OF GASTROSTOMY.}

BY A. ERNEST MAYLARD, M.B., B.S LOND., SURGEON TO THE VICTORIA INFIRMAARY, GLASGOW.

THE desirability of administering as much nutritious food as possible and the difficulty usually of doing so has led me to devise a method by which practically solid food can be introduced through the artificial fistula.

The operation employed is that known as the "KaderSenn." It consists in bringing out a cone of the cardiac end of the stomach through a small parietal wound. The base of the cone is first fixed to the abdominal parietes by four silkworm gut stitches which in the course of a few days are withdrawn. A purse-string chromic gut suture is made to transfix the sero-muscular tunic of the stomach near the base of the cone. An opening is made at the apex of the cone and into this is inserted a glass tube (see Fig. 2) which has near its end two perforations to enable the tube and the stomach to be transfixed by a chromic gut suture. By then pushing on the tube the cone becomes invaginated and is finally secured by tightening the purse-string suture. The details of the operation will perhaps be better understood by a glance at the diagrammatic illustration (Fig. 1).

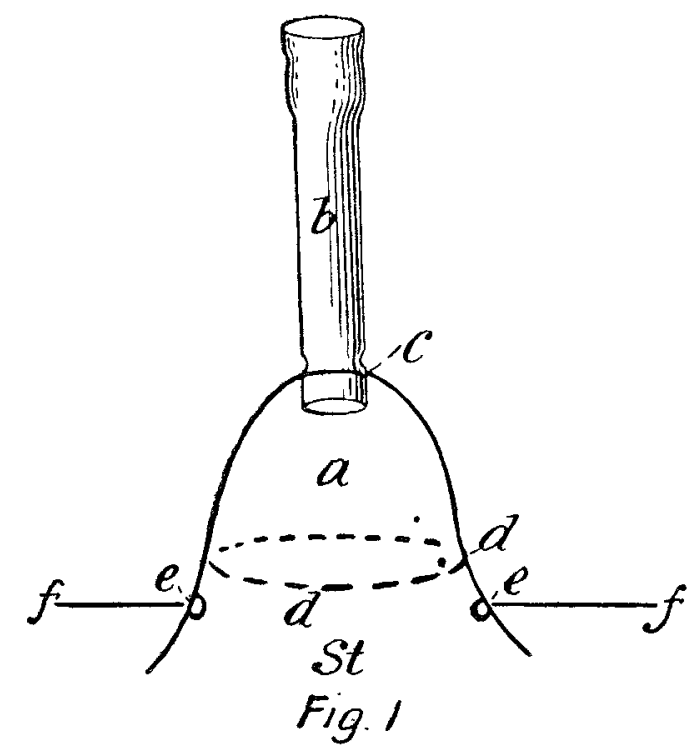

FIG. 1.-Diagrammatic representation of the operation of gastrostomy by the "Kader-Senn" method. $a$, Cone of stomach drawn out through an incision in the abdominal parietes $(f, b$, Gastrostomy glass tube with apertures at $c$ for fixation by suture of the tube into the opening at the apex of the gastric cone. $d$, Purse-string suture for tightening after invagination of tube and cone. $e, e$, Two of the four silkworm gut sutures used for fixing the base of the cone to the abdominal parietes.

I have performed this particular operation 16 times with one death. The death occurred in a patient who was in an advanced emaciated condition and on the verge of dying. The shortest times in which I have performed the operation have been six minutes with the administration of an anæs thetic; and 12 minutes when only local anæsthesia to the skin was employed. In the former case I had the advantage of the able assistance of my colleagues, Dr. Farquhar Macrae and Dr. David Lamb, the infirmary anæsthetist. The patient was an old man, aged 79 years. A tight, probably malignant, stricture existed high up in the cesophagus, and in attempting to take fluids they trickled over into the larynx and caused violent attacks of coughing. He was much enfeebled and suffered from chronic bronchitis. Speed in operating was therefore of some moment. 15 minutes may be taken as a reasonable time for the performance of the 